\title{
Brown versus White Adipose Tissue: A Mini-Review
}

\author{
Christoph H. Saely ${ }^{a-c}$ Kathrin Geiger ${ }^{b, c}$ Heinz Drexel ${ }^{a-d}$

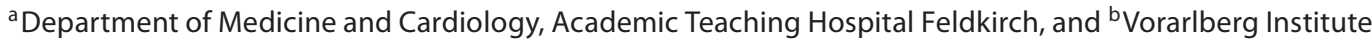 \\ for Vascular Investigation and Treatment (VIVIT), Feldkirch, Austria; ' Private University of the Principality of \\ Liechtenstein, Triesen, Liechtenstein; ${ }^{d}$ Drexel University College of Medicine, Philadelphia, Pa., USA
}

\section{Key Words}

Brown adipose tissue $\cdot$ White adipose tissue $\cdot$ Brown fat . White fat $\cdot$ Aging

\begin{abstract}
Background: Brown adipose tissue (BAT) is abundant in small mammals and in newborns and helps them to survive cold temperatures. In adults, it had long been considered to be absent or at least of no relevance. Recent investigations, however, have fuelled interest in adult BAT. Objective: We aimed at (1) summarizing structural and physiological characteristics of BAT versus white adipose tissue (WAT); (2) discussing the development of the two adipose tissue types; (3) reviewing the data available from human studies on BAT, and (4) discussing the impact of aging. Methods: We summarize recent descriptions of BAT and WAT based on the original literature and reviews in the field, with emphasis on human BAT. Results: WAT and BAT have essentially antagonistic functions: WAT stores excess energy as triglycerides and BAT is specialized in the dissipation of energy through the production of heat. Considerable amounts of BAT are present in a substantial proportion of adult humans and relatively high quantities of BAT are associated with lower body weight. With increasing age, BAT decreases and body weight increases. Conclusions: Although the available cross-sectional data
\end{abstract}

do not allow definite conclusions to be drawn concerning a causal relationship between loss of BAT and increasing body weight with advancing age or obesity-related metabolic disorders of older age, stimulation of BAT appears to be an attractive novel candidate target for the treatment of agerelated obesity.

Copyright $\odot 2010$ S. Karger AG, Basel

\section{Introduction}

Two types of adipose tissue can be distinguished, which have essentially antagonistic functions: white adipose tissue (WAT) stores excess energy as triglycerides and brown adipose tissue (BAT) is specialized in the dissipation of energy through the production of heat.

BAT is abundant in small mammals and in newborns and helps them to survive cold temperatures. In adults, it had long been considered to be absent or at least of no relevance. Recent investigations, however, have shown that adults also have metabolically active BAT and that BAT may play an important role in energy homeostasis in adults.

From a clinical point of view, BAT is thus of great interest as a potential target to treat obesity and associated metabolic disorders. This work first summarizes struc-

\section{KARGER \\ Fax +41613061234 E-Mail karger@karger.ch} www.karger.com
(C) 2010 S. Karger AG, Base 0304-324X/12/0581-0015\$38.00/0

Accessible online at: www.karger.com/ger
Christoph H. Saely, MD

Vorarlberg Institute for Vascular Investigation and Treatment (VIVIT)

Carinagasse 47

AT-6807 Feldkirch (Austria)

Tel. +435522 303 2670, Fax +435522303 7533, E-Mail vivit@lkhf.at 
Table 1. Characteristics of white and brown fat

\begin{tabular}{lll}
\hline & White fat & Brown fat \\
\hline Function & Energy storage & Heat production \\
\hline Morphology & $\begin{array}{l}\text { Single lipid droplet } \\
\text { Variable amount of mitochondria }\end{array}$ & $\begin{array}{l}\text { Multiple small vacuolae } \\
\text { Abundant mitochondria }\end{array}$ \\
\hline Characteristic proteins & Leptin & UCP1 \\
\hline Development & From Myf5-negative progenitor cells & $\begin{array}{l}\text { From Myf5-positive progenitor cells (but there are } \\
\text { also Myf5-negative brown fat cells which are derived } \\
\text { from other lineages) }\end{array}$ \\
\hline Human data & $\begin{array}{l}\text { Large amounts are associated with increased risk } \\
\text { of obesity-related disorders }\end{array}$ & $\begin{array}{l}\text { Large amounts are associated with decreased risk of } \\
\text { obesity-related disorders }\end{array}$ \\
\hline Impact of aging & $\begin{array}{l}\text { Increases with age relative to total body weight } \\
\text { Decreases with age }\end{array}$ & \begin{tabular}{l} 
Decreas \\
\hline
\end{tabular} \\
\hline
\end{tabular}

tural and physiological characteristics of BAT versus WAT and discusses the development of the two adipose tissue types. It then reviews the data available from human studies on BAT and discusses the impact of aging.

\section{Structure and Physiology}

Characteristics of white and brown fat are summarized in table 1. White adipocytes are spherical cells whose variable size mainly depends on the size of the single lipid droplet stored in them. This lipid droplet consists of triglycerides and accounts for more than $90 \%$ of the cell volume. Mitochondria in white adipocytes are thin, elongated, and variable in amount.

Brown adipocytes in contrast contain triglycerides as multiple small vacuoles; they are typically polygonal with a variable diameter. The most characteristic organelles of BAT cells are the mitochondria. They are large, spherical, packed with laminar cristae and usually numerous. Because of its greater oxygen demand brown fat also contains more capillaries than white fat. Also, nerve supply is denser in BAT than in WAT. The brown color of BAT is attributable to its high mitochondrial density and high vascularization [1].

Whereas WAT stores excess energy as triglycerides, the function of BAT is to dissipate energy through the production of heat. This is referred to as nonshivering thermogenesis [2]. Therefore, brown fat is abundant in small mammals or newborns who are predisposed to temperature loss by a small body volume to body surface ratio and for whom it is difficult to maintain an adequate core body temperature through isolation by WAT or through muscle shivering. In adult humans, brown fat has been found to be distributed throughout the cervical, supraclavicular, axillary, paravertebral, mediastinal, and upper abdominal regions [3]. This distribution appears to serve as a warming mechanism for the blood supply to vital organs.

Mitochondria in eukaryotic cells store energy as a proton gradient across the inner mitochondrial membrane. This energy is used to synthesize adenosine trisphosphate (ATP) when the protons flow down their concentration gradient across the membrane through the enzyme ATP synthase. When protons run back along the gradient without producing ATP, the stored energy is dissipated as heat. This can occur via a short-circuit route for the protons, the uncoupling protein 1 (UCP1) in the inner mitochondrial membrane [4], which immunohistochemically is the defining protein marker of BAT [2].

Most other differentially expressed genes show only relative differences between brown and white adipocytes. These include type 2 iodothyronine deiodinase; the transmembrane glycoprotein Elovl3; the fatty-acid-activated transcription factor peroxisome-proliferator-activated receptor- $\alpha$ (PPAR $\alpha$ ); the nuclear coactivator PGC$1 \alpha$, and factors involved in mitochondrial biogenesis and function. All of these genes are preferentially expressed in BAT, whereas leptin, the nuclear corepressor RIP140, and matrix protein fibrillin-1 are more highly expressed in WAT than in BAT. Among the developmental genes, homeobox genes HoxA1 and HoxC4 are preferentially expressed in human fetal BAT, whereas HoxA4 and HoxC8 are more abundant in human WAT [4].

Cold exposure and feeding increase BAT activity and UCP1 expression via norepinephrine released from the 
sympathetic nervous system. Concordantly, other $\beta$-adrenergic agonists as well as cAMP analogs increase UCP1 expression. Further stimuli that can induce UCP1 expression include thyroid hormone, insulin, thiazolidinediones, and retinoic acid. Glucocorticoids inhibit UCP1 gene expression in response to adrenergic stimulation [4]. Further, rat experiments suggest that nicotine exerts its energy expenditure-increasing effect by activating BAT function [5].

\section{Development}

Adipocytes (as well as myocytes) arise from the mesoderm [6]. During fetal development, BAT emerges earlier than WAT, which begins to develop in midgestation. It is at its maximal size relative to body weight at birth. WAT depots in humans typically increase gradually throughout life [4].

Previously, a common origin of white and brown adipocytes was assumed. However, more recent evidence does not support this concept. Rather, brown fat cells and muscle cells both seem to be derived from the same stem cells (fig. 1).

Indeed, apart from their lack of contractility, brown fat cells have much in common with muscle cells: muscle like brown fat is specialized for lipid catabolism rather than storage, is innervated by the sympathetic nervous system, contains abundant mitochondria, and facilitates adaptive thermogenesis [7]. Already in 2006, Atit et al. [8] clearly showed that BAT and muscle (and dermis) had the same developmental origin. Timmons et al. [9] observed that both muscle cells and brown fat cells, in contrast to white adipose fat cells, carry the marker myogenic factor 5 (Myf5), which suggests a bipotent precursor cell for muscle and brown adipocytes (but does not rule out the possibility that these cells are derived from separate lineages of Myf5-positive cells). These findings were confirmed and extended by Seale et al. [10, 11]. These authors showed that the Zn-finger transcriptional regulator PRD1-BF1-RIZ1 homologous domain containing 16 (PRDM16) controls a bidirectional cell fate switch between skeletal myoblasts and brown fat cells. Loss of PRDM16 from brown fat precursors causes a loss of brown fat characteristics and promotes muscle differentiation. Conversely, ectopic expression of PRDM16 in myoblasts induces their differentiation into brown fat cells. PRDM16 stimulates brown adipogenesis by binding to PPAR- $\gamma$ and activating its transcriptional function [11]. Also, bone morphogenetic protein 7 (BMP7) was shown to specifically direct brown adipocyte differentia-

Brown versus White Adipose Tissue: A Mini-Review

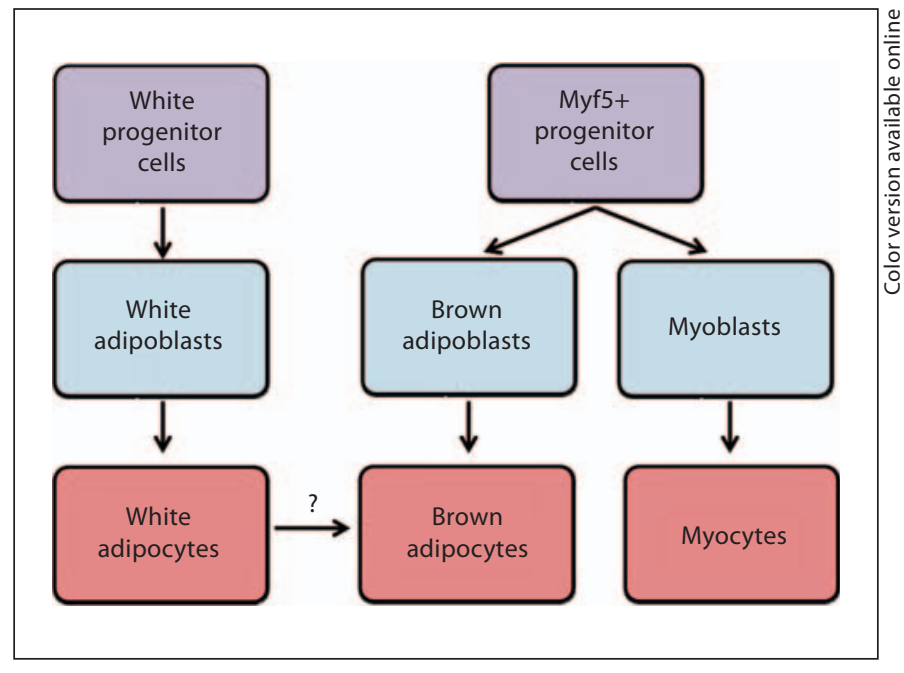

Fig. 1. Development of white and brown fat. Brown fat shares common progenitor cells with muscle cells. It is uncertain whether white fat cells transdifferentiate into brown fat cells.

tion, including induction of PRDM16 and UCP1 gene expression [12]. Synthetic chemicals or endogenous factors that activate PRDM16 function or mimic its action in brown adipocyte development are of potential interest as future antiobesity drugs.

Importantly, however, there are two types of brown fat cells [11]: besides the Myf5-positive cells described above, which are located at classic locations for brown fat cells, there are brown fat cells interspersed in WAT which are negative for the Myf5 marker and thus are derived from another lineage: they probably stem from the activation of dormant precursor cells. Transdifferentiation from white to brown fat cells has been discussed as one possibility as well [1]. An interesting recent study demonstrates that inhibition of peripheral cannabinoid type 1 receptor (CB1R) action in adipocytes directly promotes transdifferentiation of white adipocytes into a mitochondrionrich, thermogenic brown fat phenotype [13]. Enhanced thermogenesis, therefore, may represent a peripheral mechanism contributing to the weight loss and improved glucose homeostasis induced by the CB1R blocking agent rimonabant.

\section{Human Data}

High-quality data on BAT in humans remain scarce. In human fetuses and newborns, BAT is found in axillary, cervical, perirenal, and periadrenal regions [4] but de- 
creases shortly after birth and has been considered to be irrelevant in adults until recently. Several investigations, however, now have conclusively demonstrated the presence and, more importantly, the functional relevance of BAT in adults.

Already in 1981, an anatomical study described BAT in the neck region of outdoor workers but not in indoor workers [14]. The authors suggested a role of BAT in temperature regulation. Another morphological study [15] found that there is a large amount of a tissue around the adrenal glands and kidneys in patients with pheochromocytoma that fulfills the ultrastructural and biochemical criteria for BAT. This pointed at the possibility of BAT stimulation through adrenergic mechanisms.

Brown adipocytes are metabolically highly active and can take up high amounts of glucose. Tissues with high rates of glucose incorporation can be identified with positron emission tomography (PET) using radioactively labeled fluorodeoxyglucose (FDG). This technique is used clinically to detect metabolically active tumor sites. For a long time, false-positive results had been obtained in the parasternal or supraclavicular regions. By simultaneous examinations with FDG-PET and X-ray computed tomography (CT) these sites could be identified as adipose tissue. This PET-CT technique has disclosed large amounts of metabolically active BAT in adult humans.

A series of investigators have retrospectively examined scans from clinical monitoring studies of cancer patients. As these studies were performed under environmental conditions that could affect the outcome in an uncontrolled way, the quantitative data reported are not meaningful and will not be discussed further here [1626].

In a study by Garcia et al. [27], two teenage female patients with abnormal FDG uptake patterns on PET scans performed with oral benzodiazepine administration underwent repeat imaging in temperature-controlled environment settings. The authors observed a resolution of supraclavicular FDG uptake with temperature control in these two patients in whom benzodiazepines had no effect.

Another study [28] described bilateral FDG tracer accumulation in the shoulder and lower neck of a patient with extra-adrenal pheochromocytoma and high plasma norepinephrine levels. The authors suggested that excessive sympathetic stimulation by high circulating catecholamine concentrations may have augmented the metabolic activity and tracer uptake in BAT and that radionuclide imaging can noninvasively visualize human BAT in terms of metabolic and functional activity.
An important limitation of these studies is that no histological verification of BAT was performed. In 2007, Nedergaard et al. [29] reviewed those observations from PET-CT scans in a physiological perspective. Overall, the data extracted from the literature suggested that human depots of putative brown fat are somewhat differently located from those in rodents, the main depots being found in the supraclavicular and the neck regions with some additional paravertebral, mediastinal, para-aortic, and suprarenal localizations. From the reviewed data the overall conclusion was reached that BAT activity in man is induced by acute cold and is stimulated by the sympathetic nervous system. The prevalence of active BAT in the population was estimated to be in the range of some tens of percent.

Scientific interest in BAT was recently fuelled by the publication of investigations in the New England Journal of Medicine [24, 30, 31], which not only conclusively demonstrated the presence of BAT in adult humans but also its dependence on environmental temperature and its association with body weight.

Using PET, Virtanen et al. [31] found that cold-induced glucose uptake was increased by a factor of 15 in paracervical and supraclavicular adipose tissue in 5 healthy subjects. The authors obtained biopsy specimens of this tissue from the first 3 consecutive subjects and documented messenger RNA (mRNA) and protein levels of the brown-adipocyte marker UCP1. Together with morphologic assessment, which showed numerous multilocular, intracellular lipid droplets, and with the results of biochemical analysis, these findings documented the presence of substantial amounts of metabolically active BAT in healthy adult humans.

van Marten Lichtenbelt et al. [30] studied 24 healthy men of whom 14 were overweight or obese under thermoneutral conditions and during mild cold exposure. BAT activity was determined with the use of integrated FDG PET-CT. Body composition and energy expenditure were measured with the use of dual-energy X-ray absorptiometry and indirect calorimetry. BAT activity was observed in 23 of the 24 subjects (96\%) during cold exposure but not under thermoneutral conditions. This activity was significantly lower in the overweight or obese subjects than in the lean subjects. Body mass index (BMI) and percentage of body fat were both significantly negatively correlated with BAT, whereas the resting metabolic rate was significantly positively correlated. The authors concluded that the percentage of young men with BAT was high, but that its activity was reduced in overweight or obese men. 
In response to these articles, several interesting observations were published as letters to the editor. One important comment hypothesized that the prevalence of BAT may have been underestimated because no repeat measurements were performed. Lee et al. [32] analyzed 4,834 consecutive PET-CT scans of 2,934 patients. BAT was detected in 250 patients, yielding a prevalence of $8.5 \%$. Among 747 patients who underwent scanning more than once, 145 patients had at least one positive scan, yielding a much higher prevalence of almost $20 \%$.

Timmons and Pedersen [33], using gene profiling, found that mRNA of the BAT marker UCP1 was positively associated with BMI in human subcutaneous adipose tissue from 33 subjects. These associations with BMI were in the opposite direction as those previously observed and were markedly influenced by the presence of diabetes. The authors pointed out that disseminated brown adipocytes within the large subcutaneous adipose tissue mass may cumulatively represent substantial brown adipocyte activity that may not be detected with the use of PET-CT or crude biochemical studies. A limitation of this observation, however, is that mRNA expression cannot be translated into the amount of BAT activity. Further studies would be needed to expand observations on UCP1 mRNA into hypotheses about functional BAT activity in subcutaneous fat.

Saito et al. [34] also examined the prevalence of metabolically active BAT in healthy adult humans and the effects of cold exposure and adiposity. FDG uptake into adipose tissue was measured by PET-CT in 56 healthy volunteers ( 31 male and 25 female subjects) aged 23-65 years. When exposed to cold for $2 \mathrm{~h}, 17$ of 32 subjects aged $23-35$ years and 2 of 24 subjects aged 38-65 years showed a substantial FDG uptake into adipose tissue of the supraclavicular and paraspinal regions, whereas they showed no detectable uptake when kept warm. Histological examinations confirmed the presence of brown adipocytes in these regions. The cold-activated FDG uptake was increased in winter compared with summer and was inversely related to BMI and total and visceral fat areas estimated from CT images at the umbilical level. These findings indicate a high prevalence of metabolically active BAT in adult humans and suggest a role in the control of body temperature and adiposity. The authors state that if BAT were fully activated, it would burn an amount of energy equivalent to approximately $4.1 \mathrm{~kg}$ of adipose tissue over a year.

In another recent work, Sacks et al. [35] found that UCP1 is expressed at high levels in epicardial fat as compared to other fat depots. The possibility should therefore be considered that epicardial fat functions like brown fat to protect the myocardium and coronary vessels from hypothermia. This process could be blunted in the elderly.

Zingaretti et al. [36] analyzed samples of adipose tissue from the neck of 35 patients undergoing surgery for thyroid diseases. In $1 / 3$ of the subjects (the younger and leaner), distinct islands composed of UCP1-immunoreactive brown adipocytes could clearly be discerned. The brown adipose islands were richly sympathetically innervated (indicating acute central control), whereas adjacent white adipose areas were not. Cells with features of brown adipocyte precursors were found in pericapillary areas.

A common shortcoming of the data discussed is the cross-sectional approach which does not allow assumption of a causal relationship between low amounts of active BAT and overweight or obesity. Alternatively, overweight patients and in particular diabetic patients may be unable to sustain BAT stores. Lean adults may further require increased BAT metabolism for nonshivering thermogenesis to maintain body temperature. Whether thinner patients have more BAT to meet these thermogenic needs or are thin because they have more active BAT at this stage is a classical hen-and-egg question which requires further study.

\section{The Impact of Aging}

Mass, distribution and function of white fat undergo dramatic changes throughout life. Fat mass reaches a peak by middle or early old age, followed by a substantial decline in advanced old age. However, the observed decrease in total body fat with old age does not coincide with a decline in percent body fat, which typically remains constant or increases. The age-associated decline in the sizes of adipose depots is accompanied by the accumulation of fat outside adipose tissue and loss of lean body mass, particularly of muscle. Ectopic fat accumulation occurs in bone marrow, muscle, liver, and at other sites, potentially contributing to age-dependent dysfunction of these tissues [37].

Further, different fat depots undergo age-related changes at different rates. Retro-orbital and peripheral subcutaneous fat, for example, tend to be lost first, whereas visceral fat is rather preserved. The earlier loss of subcutaneous fat and consequent relative increase in intraabdominal fat with aging could predispose to metabolic dysfunction and related health complications [37]. This indicates that depot-specific changes in fat tissue function with aging may contribute to development of age- 
related metabolic disorders. On a cellular level, the capacity of preadipocytes to become fully functional mature adipocytes declines with age [37]. Age-dependent lipotoxicity is related to a decreased capacity of adipose tissue to store free fatty acids. The resulting lipotoxic environment is detrimental to nonadipose tissues. This may contribute to systemic lipotoxicity, and the increased prevalence of metabolic syndrome in older populations.

The functionality of BAT is impaired, too, with increasing age. The ability to regulate body temperature diminishes with age both in humans and rodents $[38,39]$. This decline in thermoregulation often results in a decrease in cold tolerance and in impaired body weight control, promoting an age-related increase in body weight. In rodent models, the age-associated decline in thermoregulation has been related to BAT atrophy [40] which parallels a loss of UCP1 activity [41]. This age-related decline in BAT functionality has been shown to be influenced by gender: females show a less severe loss of thermogenic capacity with advancing age than males [42]. Pathophysiologically, impairment of BAT function with increasing age appears to be mediated, at least in part, by disturbed adrenergic signaling $[43,44]$.

Ueno et al. [45] investigated the effect of aging on BAT activity in lean and obese (ob/ob) mice. Unlike old lean animals, old obese animals exhibited decreased expression of mRNA for UCP1. These findings suggest a marked decrease in BAT thermogenic capacity and activity in old obese mice. Age and obesity thus seem to interact regarding their association with low amounts of BAT.

The interaction between body weight and age as concerns their association with low amounts of BAT, which was observed in mice, may be present also in humans: in the above study by Saito et al. [34], the prevalence of coldactivated BAT activity decreased in elderly subjects: in a total of 24 elderly subjects, BAT was detected in only 2 males who were rather lean. In the above-mentioned study by Zingaretti et al. [36], the prevalence of brown fat in the cervical adipose tissue was also positively correlated with young age and leanness. The authors pointed out that because of the covariation of these two factors, it was not possible to ascribe the high prevalence to young age or leanness separately.

Mitochondria are the predominant cell organelles in brown adipocytes, as has been discussed above. Mitochondria also play a crucial role in the aging process since they are the main source of free radicals and, at the same time, the most immediate target of oxidative damage. In many species, caloric restriction can increase lifespan and delay the rate of aging [46]. The mechanisms under- lying these beneficial effects of caloric restriction are not completely understood. However, it has been demonstrated that caloric restriction reduces the generation of free radicals by mitochondria [47] and prevents the ageassociated decline in mitochondrial function [48].

Valle et al. [49] investigated the effect of long-term caloric restriction on BAT mitochondrial function and biogenesis. In their study, caloric restriction induced resistance to the loss of total and mitochondrial protein, COX activity and uncoupling capacity with advancing age. These results demonstrated that caloric restriction prevents the age-associated decline of mitochondrial function in BAT.

Far from being an inert reservoir for triglycerides, fat tissue is a highly active endocrine organ producing a wide array of peptide hormones, referred to as adipokines [50]. The pathophysiological role of some of these peptide hormones has been extensively studied in recent years.

For example, adiponectin, the most abundant peptide secreted by adipocytes, enhances insulin sensitivity [50]. Low serum levels of adiponectin are associated with the metabolic syndrome and coronary atherosclerosis [51]. Studies on aging humans revealed that enhanced adiponectin values are a distinctive feature of centenarians [52]. In humans, there is a significant positive relationship between plasma adiponectin and age, even after adjustment for visceral adiposity [53].

Leptin, another important adipocyte-derived peptide hormone plays an important role in the regulation of food intake and thermogenesis [50]. Insufficient action of leptin causes a reduction in metabolic rate in ob/ob mice [54]. Leptin resistance has been implicated in the pathogenesis of obesity-related complications involving abnormalities of lipid metabolism that resemble those of old age. To determine whether development of leptin resistance in advancing age might account for such abnormalities, an interesting study [55] compared the effects of hyperleptinemia induced by adenovirus gene transfer in 2-month-old and 18-month-old lean wild-type Zucker diabetic fatty rats. The leptin-induced decline in food intake, body weight, and body fat in old rats was only 25 , 50 , and $16 \%$, respectively, of that of young rats. Whereas in young rats, plasma free fatty acids exhibited a $44 \%$ and triacylglycerol a $94 \%$ decrease, neither changed in the older rats. In hyperleptinemic young rats, adipocyte expression of preadipocyte factor 1 increased dramatically and leptin mRNA virtually disappeared; there was increased expression of acyl CoA oxidase, carnitine palmitoyl transferase 1, and their transcription factor PPAR $\alpha$, accounting for the reduction in body fat. These hyperlep- 
tinemia-induced changes were profoundly reduced in the old rats. On a high-fat diet, old rats consumed $28 \%$ more calories than the young and gained 1.5 times as much fat, despite greater endogenous hyperleptinemia. These data illustrate that the actions of leptin decline with age and that this could account for the associated abnormalities in lipid metabolism in the elderly. The role of obesity with regard to the development of leptin resistance during aging is not definitely clear. Whereas some data point to a causal role of obesity in the development of leptin resistance [56] other data suggest that obesity develops as a consequence of leptin resistance [57].

Of note, leptin also facilitates long-term potentiation and synaptic plasticity in the hippocampus, promotes $\beta$ amyloid clearance, and improves memory function in animal models of aging and Alzheimer's disease; circulating leptin was recently shown to be associated with a reduced incidence of dementia and Alzheimer's disease and with brain volume in asymptomatic older adults [58].

Although the discovery of longevity genes supports the concept that life span is genetically determined, adipose tissue seems to be a pivotal organ in the aging process and in the determination of life span, as has been reviewed by Bluher [59]: leanness and caloric restriction increase longevity in various organisms, including mammals. Increased longevity in mice with a fat-specific disruption of the insulin receptor gene (FIRKO) suggests that reduced adiposity leads to an extended life span even in the presence of normal or increased food intake. Reduced fat mass also has an impact on longevity in a number of other model organisms. In Drosophila, a specific reduction in body fat through overexpression of the forkhead type transcription factor (dFOXO) extends life span.

One possible gene mediating the life-extending effect of caloric restriction is silent information regulator 2 (SIR2), a member of the family of sirtuin histone deacet- ylases. SIR2 has been shown to extend lifespan in yeast, worms and flies [60]. The activation of sirtuin 1 (SIRT1), the mammalian ortholog of SIR2, resulted in enhanced lipid oxidation in BAT, skeletal muscle and liver cells and protected mice against diet-induced insulin resistance and obesity [61]. Further, SIRT1 regulates acetylation and transcriptional activity of FOXO, a member of the forkhead transcription factors, in response to oxidative stress [62]. Deacetylation of FOXO3a results in the activation of genes involved in cell cycle arrest and resistance to oxidative stress, away from its transcriptional targets involved in apoptosis towards longevity [63]. Interestingly, resveratrol, which is present in grapes and red wine, is a potent activator of SIRT1 and inhibits preadipocyte proliferation and adipogenic differentiation in a SIRT1-dependent manner [64].

\section{Conclusion}

Considerable amounts of BAT are present in a substantial proportion of adult humans and relatively high quantities of brown fat are associated with lower body weight. With increasing age, BAT decreases and body weight increases. Although the available cross-sectional data do not allow definite conclusions to be drawn concerning a causal relationship between loss of BAT and increasing body weight with advancing age or with the obesity-related metabolic disorders of older age, stimulation of BAT appears an attractive novel candidate target for the treatment of age-related obesity.

\section{Acknowledgements}

This work was supported by the Austrian Science Fund (FWF, Project 21057).

\section{References}

Brown versus White Adipose Tissue: A Mini-Review
1 Cinti S: Transdifferentiation properties of adipocytes in the adipose organ. Am J Physiol Endocrinol Metab 2009. Epub ahead of print.

2 Mattson MP: Perspective: does brown fat protect against diseases of aging? Ageing Res Rev 2010;9:69-76.

-3 Wehrli NE, Bural G, Houseni M, Alkhawaldeh K, Alavi A, Torigian DA: Determination of age-related changes in structure and function of skin, adipose tissue, and skeletal muscle with computed tomography, magnetic resonance imaging, and positron emission tomography. Semin Nucl Med 2007;37:195205.

\footnotetext{
4 Gesta S, Tseng YH, Kahn CR: Developmental origin of fat: tracking obesity to its source. Cell 2007;131:242-256.

5 Mano-Otagiri A, Iwasaki-Sekino A, Ohata $\mathrm{H}$, Arai K, Shibasaki T: Nicotine suppresses energy storage through activation of sympathetic outflow to brown adipose tissue via corticotropin-releasing factor type 1 receptor. Neurosci Lett 2009;455:26-29.

6 Enerback S: The origins of brown adipose tissue. N Engl J Med 2009;360:2021-2023.

7 Farmer SR: Brown fat and skeletal muscle: unlikely cousins? Cell 2008;134:726-727.
} 
-8 Atit R, Sgaier SK, Mohamed OA, Taketo MM, Dufort D, Joyner AL, Niswander L, Conlon RA: $\beta$-Catenin activation is necessary and sufficient to specify the dorsal dermal fate in the mouse. Dev Biol 2006;296: 164-176.

$\checkmark 9$ Timmons JA, Wennmalm K, Larsson O, Walden TB, Lassmann T, Petrovic N, Hamilton DL, Gimeno RE, Wahlestedt C, Baar K, Nedergaard J, Cannon B: Myogenic gene expression signature establishes that brown and white adipocytes originate from distinct cell lineages. Proc Natl Acad Sci USA 2007; 104:4401-4406.

-10 Seale P, Kajimura S, Yang W, Chin S, Rohas LM, Uldry M, Tavernier G, Langin D, Spiegelman BM: Transcriptional control of brown fat determination by PRDM16. Cell Metab 2007;6:38-54.

- 11 Seale P, Bjork B, Yang W, Kajimura S, Chin S, Kuang S, Scime A, Devarakonda S, Conroe HM, Erdjument-Bromage H, Tempst P, Rudnicki MA, Beier DR, Spiegelman BM: PRDM16 controls a brown fat/skeletal muscle switch. Nature 2008;454:961-967.

-12 Tseng YH, Kokkotou E, Schulz TJ, Huang TL, Winnay JN, Taniguchi CM, Tran TT, Suzuki R, Espinoza DO, Yamamoto Y, Ahrens MJ, Dudley AT, Norris AW, Kulkarni RN, Kahn CR: New role of bone morphogenetic protein 7 in brown adipogenesis and energy expenditure. Nature 2008;454:1000-1004.

-13 Perwitz N, Wenzel J, Wagner I, Buning J, Drenckhan M, Zarse K, Ristow M, Lilienthal W, Lehnert H, Klein J: Cannabinoid type 1 receptor blockade induces transdifferentiation towards a brown fat phenotype in white adipocytes. Diabetes Obes Metab 2010;12: 158-166.

14 Huttunen P, Hirvonen J, Kinnula V: The occurrence of brown adipose tissue in outdoor workers. Eur J Appl Physiol Occup Physiol 1981;46:339-345.

15 Ricquier D, Nechad M, Mory G: Ultrastructural and biochemical characterization of human brown adipose tissue in pheochromocytoma. J Clin Endocrinol Metab 1982; 54:803-807.

16 Cohade C, Mourtzikos KA, Wahl RL: 'USAFat': prevalence is related to ambient outdoor temperature-evaluation with ${ }^{18} \mathrm{~F}$-FDG PET/ CT. J Nucl Med 2003;44:1267-1270.

$\checkmark 17$ Cohade C, Osman M, Pannu HK, Wahl RL: Uptake in supraclavicular area fat ('USAfat'): description on ${ }^{18}$ F-FDG PET/CT. J Nucl Med 2003;44:170-176.

-18 Yeung HW, Grewal RK, Gonen M, Schoder H, Larson SM: Patterns of ${ }^{18}$ F-FDG uptake in adipose tissue and muscle: a potential source of false-positives for PET. J Nucl Med 2003; 44:1789-1796.

-19 Truong MT, Erasmus JJ, Munden RF, Marom EM, Sabloff BS, Gladish GW, Podoloff DA, Macapinlac HA: Focal FDG uptake in mediastinal brown fat mimicking malignancy: a potential pitfall resolved on PET/CT. AJR Am J Roentgenol 2004;183:1127-1132.
20 Hany TF, Gharehpapagh E, Kamel EM, Buck A, Himms-Hagen J, von Schulthess GK: Brown adipose tissue: a factor to consider in symmetrical tracer uptake in the neck and upper chest region. Eur J Nucl Med Mol Imaging 2002;29:1393-1398.

21 Sturkenboom MG, Franssen EJ, Berkhof J, Hoekstra OS: Physiological uptake of $\left[{ }^{18} \mathrm{~F}\right]$ fluorodeoxyglucose in the neck and upper chest region: are there predictive characteristics? Nucl Med Commun 2004;25:11091111.

22 Dobert N, Menzel C, Hamscho N, Wordehoff W, Kranert WT, Grunwald F: Atypical thoracic and supraclavicular FDG-uptake in patients with Hodgkin's and non-Hodgkin's lymphoma. Q J Nucl Med Mol Imaging 2004; 48:33-38.

23 Rousseau C, Bourbouloux E, Campion L, Fleury N, Bridji B, Chatal JF, Resche I, Campone $\mathrm{M}$ : Brown fat in breast cancer patients: analysis of serial ${ }^{18} \mathrm{~F}-\mathrm{FDG}$ PET/CT scans. Eur J Nucl Med Mol Imaging 2006;33:785791.

-24 Cypess AM, Lehman S, Williams G, Tal I, Rodman D, Goldfine AB, Kuo FC, Palmer EL, Tseng YH, Doria A, Kolodny GM, Kahn CR: Identification and importance of brown adipose tissue in adult humans. N Engl J Med 2009;360:1509-1517.

25 Stefan N, Pfannenberg C, Haring HU: The importance of brown adipose tissue. $\mathrm{N}$ Engl J Med 2009;361:416-417.

26 Au-Yong IT, Thorn N, Ganatra R, Perkins AC, Symonds ME: Brown adipose tissue and seasonal variation in humans. Diabetes 2009;58:2583-2587.

-27 Garcia CA, Van ND, Majd M, Atkins F, Acio E, Sheikh A, Butler C: Benzodiazepine-resistant 'brown fat' pattern in positron emission tomography: two case reports of resolution with temperature control. Mol Imaging Biol 2004;6:368-372.

28 Fukuchi K, Tatsumi M, Ishida Y, Oku N, Hatazawa J, Wahl RL: Radionuclide imaging metabolic activity of brown adipose tissue in a patient with pheochromocytoma. Exp Clin Endocrinol Diabetes 2004;112:601-603.

29 Nedergaard J, Bengtsson T, Cannon B: Unexpected evidence for active brown adipose tissue in adult humans. Am J Physiol Endocrinol Metab 2007;293:E444-E452.

30 van Marken Lichtenbelt WD, Vanhommerig JW, Smulders NM, Drossaerts JM, Kemerink GJ, Bouvy ND, Schrauwen P, Teule GJ: Coldactivated brown adipose tissue in healthy men. N Engl J Med 2009;360:1500-1508.

31 Virtanen KA, Lidell ME, Orava J, Heglind M, Westergren R, Niemi T, Taittonen M, Laine J, Savisto NJ, Enerback S, Nuutila P: Functional brown adipose tissue in healthy adults. N Engl J Med 2009;360:1518-1525. 32 Lee P, Ho KK, Fulham MJ: The importance
of brown adipose tissue. N Engl J Med 2009; 361:418-420.
33 Timmons JA, Pedersen BK: The importance of brown adipose tissue. N Engl J Med 2009; 361:415-416.

34 Saito M, Okamatsu-Ogura Y, Matsushita M, Watanabe K, Yoneshiro T, Nio-Kobayashi J, Iwanaga T, Miyagawa M, Kameya T, Nakada K, Kawai Y, Tsujisaki M: High incidence of metabolically active brown adipose tissue in healthy adult humans: effects of cold exposure and adiposity. Diabetes 2009;58:15261531.

-35 Sacks HS, Fain JN, Holman B, Cheema P, Chary A, Parks F, Karas J, Optican R, Bahouth SW, Garrett E, Wolf RY, Carter RA, Robbins T, Wolford D, Samaha J: Uncoupling protein-1 and related messenger ribonucleic acids in human epicardial and other adipose tissues: epicardial fat functioning as brown fat. J Clin Endocrinol Metab 2009;94: 3611-3615.

36 Zingaretti MC, Crosta F, Vitali A, Guerrieri M, Frontini A, Cannon B, Nedergaard J, Cinti S: The presence of UCP1 demonstrates that metabolically active adipose tissue in the neck of adult humans truly represents brown adipose tissue. FASEB J 2009;23:3113-3120.

37 Cartwright MJ, Tchkonia T, Kirkland JL: Aging in adipocytes: potential impact of inherent, depot-specific mechanisms. Exp Gerontol 2007;42:463-471.

38 McDonald RB, Horwitz BA, Hamilton JS, Stern JS: Cold- and norepinephrine-induced thermogenesis in younger and older Fischer 344 rats. Am J Physiol 1988;254:R457-R462.

39 Norman DC, Grahn D, Yoshikawa TT: Fever and aging. J Am Geriatr Soc 1985;33:859863.

40 Scarpace PJ, Matheny M, Borst SE: Thermogenesis and mitochondrial GDP binding with age in response to the novel agonist CGP-12177A. Am J Physiol 1992;262:E185E190.

41 Cannon B, Nedergaard J: Brown adipose tissue: function and physiological significance. Physiol Rev 2004;84:277-359.

-42 McDonald RB, Day C, Carlson K, Stern JS, Horwitz BA: Effect of age and gender on thermoregulation. Am J Physiol 1989; 257:R700-R704.

43 Langin D, Tavernier G, Lafontan M: Regulation of $\beta 3$-adrenoceptor expression in white fat cells. Fundam Clin Pharmacol 1995;9:97106.

44 Scarpace PJ, Dove J, Matheny M: Effects of age on $\beta$-adrenergic subtype activation of adenylyl cyclase in brown adipose tissue. Proc Soc Exp Biol Med 1996;213:262-267.

45 Ueno N, Oh-ishi S, Segawa M, Nishida M, Fukuwatari Y, Kizaki T, Ookawara T, Ohno $\mathrm{H}$ : Effect of age on brown adipose tissue activity in the obese (ob/ob) mouse. Mech Ageing Dev 1998;100:67-76.

46 Weindruch R, Sohal RS: Seminars in medicine of the Beth Israel Deaconess Medical Center. Caloric intake and aging. N Engl J Med 1997;337:986-994. 
-47 Colom B, Oliver J, Roca P, Garcia-Palmer FJ: Caloric restriction and gender modulate cardiac muscle mitochondrial $\mathrm{H}_{2} \mathrm{O}_{2}$ production and oxidative damage. Cardiovasc Res 2007; 74:456-465.

48 Hepple RT, Baker DJ, McConkey M, Murynka T, Norris R: Caloric restriction protects mitochondrial function with aging in skeletal and cardiac muscles. Rejuvenation Res 2006;9:219-222.

-49 Valle A, Guevara R, Garcia-Palmer FJ, Roca $\mathrm{P}$, Oliver J: Caloric restriction retards the age-related decline in mitochondrial function of brown adipose tissue. Rejuvenation Res 2008;11:597-604.

50 Galic S, Oakhill JS, Steinberg GR: Adipose tissue as an endocrine organ. Mol Cell Endocrinol 2010;316:129-139.

-51 Saely CH, Risch L, Hoefle G, Rein P, Muendlein A, Marte T, Aczel S, Langer P, Drexel H: Low serum adiponectin is independently associated with both the metabolic syndrome and angiographically determined coronary atherosclerosis. Clin Chim Acta 2007;383:97-102.

52 Bik W, Baranowska B: Adiponectin - a predictor of higher mortality in cardiovascular disease or a factor contributing to longer life? Neuro Endocrinol Lett 2009;30:180-184.
\$3 Koh SJ, Hyun YJ, Choi SY, Chae JS, Kim JY, Park S, Ahn CM, Jang Y, Lee JH: Influence of age and visceral fat area on plasma adiponectin concentrations in women with normal glucose tolerance. Clin Chim Acta 2008;389: 45-50.

54 Breslow MJ, Min-Lee K, Brown DR, Chacko VP, Palmer D, Berkowitz DE: Effect of leptin deficiency on metabolic rate in ob/ob mice. Am J Physiol 1999;276:E443-E449.

55 Wang ZW, Pan WT, Lee Y, Kakuma T, Zhou YT, Unger RH: The role of leptin resistance in the lipid abnormalities of aging. FASEB J 2001;15:108-114.

56 Fernandez-Galaz C, Fernandez-Agullo T, Perez C, Peralta S, Arribas C, Andres A, Carrascosa JM, Ros M: Long-term food restriction prevents ageing-associated central leptin resistance in Wistar rats. Diabetologia 2002;45:997-1003.

57 Gabriely I, Ma XH, Yang XM, Rossetti L, Barzilai N: Leptin resistance during aging is independent of fat mass. Diabetes 2002;51: 1016-1021.

58 Lieb W, Beiser AS, Vasan RS, Tan ZS, Au R, Harris TB, Roubenoff R, Auerbach S, DeCarli C, Wolf PA, Seshadri S: Association of plasma leptin levels with incident Alzheimer disease and MRI measures of brain aging. JAMA 2009;302:2565-2572.

59 Bluher M: Fat tissue and long life. Obes Facts 2008;1:176-182.
60 Guarente L, Picard F: Calorie restriction the SIR2 connection. Cell 2005;120:473482 .

61 Feige JN, Lagouge M, Canto C, Strehle A, Houten SM, Milne JC, Lambert PD, Mataki C, Elliott PJ, Auwerx J: Specific SIRT1 activation mimics low energy levels and protects against diet-induced metabolic disorders by enhancing fat oxidation. Cell Metab 2008;8: 347-358.

62 Yang Y, Hou H, Haller EM, Nicosia SV, Bai W: Suppression of FOXO1 activity by FHL2 through SIRT1-mediated deacetylation. EMBO J 2005;24:1021-1032.

63 Brunet A, Sweeney LB, Sturgill JF, Chua KF, Greer PL, Lin Y, Tran H, Ross SE, Mostoslavsky R, Cohen HY, Hu LS, Cheng HL, Jedrychowski MP, Gygi SP, Sinclair DA, Alt FW, Greenberg ME: Stress-dependent regulation of FOXO transcription factors by the SIRT1 deacetylase. Science 2004;303:20112015.

64 Fischer-Posovszky P, Kukulus V, Tews D, Unterkircher T, Debatin KM, Fulda S, Wabitsch M: Resveratrol regulates human adipocyte number and function in a Sirt1dependent manner. Am J Clin Nutr 2010;92: 5-15 